\title{
Complex pediatric wound care with a dedicated pediatric wound care service: a review of our I2-year experience
}

This article was published in the following Dove Press journal:

Chronic Wound Care Management and Research

24 February 2016

Number of times this article has been viewed

\section{Kathryn Q Bernabe}

Department of General Surgery, Division of Pediatric Surgery, St Louis Children's Hospital-Washington University, St Louis, MO, USA
Correspondence: Kathryn Q Bernabe Division of Pediatric Surgery, St Louis Children's Hospital, One Children's Place, St Louis, MO 63110, USA

$\mathrm{Tel}+\mathrm{I} 3$ I 44546022

Fax +I 3|4 4542442

Email bernabek@wudosis.wustl.edu
Abstract: Pediatric skin and soft tissue infections and wounds are on the rise. The effects of this increase are being felt in the emergency department and inpatient hospital settings. The costs associated with evaluation and management of children with surgical wounds and soft tissue infections are not insignificant. This is a review of our single institutional experience with delivery of wound care for the increasing pediatric skin infection and wound population utilizing a specific model for the past 12 years. It is especially tailored for complex pediatric wounds that would otherwise be cared for in the operating room setting.

Keywords: pediatric wounds, pediatric sedation, soft tissue infection, abscess

\section{Introduction}

In the pediatric population, care of skin and soft tissue infection (SSTI) and traumatic open wounds is a frequent sight in the emergency department or pediatrician's office. The volume of these conditions is not insignificant and has been greatly increasing over the years. The rise appears to accompany the emergence of community-acquired methicillin-resistant Staphylococcus aureus. ${ }^{1}$ If the wound or infection is complex, hospital admission may be required for adequate pain management and repeated wound dressing care. Hospitalizations for pediatric SSTI accounted for 1\% of all hospitalizations in a recent review of the Kids' Inpatient Data Base by Lopez et al. ${ }^{2}$ Using the same data base, Lautz et al reported that hospital admissions for SSTIs in children increased by about 44\% from 2003 to $2006 .{ }^{3}$ With regard to estimating the volume of pediatric open wounds and burns, the literature is limited. Again, the Kids' Inpatient Data Base captures admissions for open wounds while limited cases of firearm wounds and burns can be found in databases such as the Healthcare Cost and Utilization Project and American Burn Association National Burn Repository. ${ }^{4-7}$ Lautz et al estimated the in-hospital cost of caring for an SSTI to be between $\$ 3,521$ and $\$ 4,296$ per patient. $^{3}$ The care for SSTIs and wounds in children can often involve surgical intervention and ongoing wound care. In 2009, the incidence of incision and drainage procedures for SSTIs increased from $21 \%$ to $44 \%$, as reported by Lopez et al. ${ }^{2}$ Limited data exist for the cost associated with care of other skin and soft tissue wounds sustained by children, including traumatic wounds. Carey et al elucidated that the cost for inpatient pediatric burn wound care is estimated to be as high as $\$ 16,331$ per patient. ${ }^{8}$ The rise in pediatric SSTIs has resulted in an increase in resource utilization. Lopez et al found that mean charges per hospitalization have increased by $71.5 \% .^{2}$ To meet the needs of the increasing pediatric population of SSTI and other wounds, our institution has 
developed a model that is cost-effective, contributes to the hospital margin, improves resource utilization, and does not compromise standard wound care.

\section{History}

Performing an invasive procedure for a soft tissue infection or wound in a child is most often done with some type of analgesia and sedation due to the anxiety and pain involved. ${ }^{9-11}$ Incision and drainage of an abscess, burn debridement, wound cavity cleansing, and wound cavity packing with dressing changes cause pain. Even before the procedure is performed, anxiety is experienced by the child and even the family. The pediatric burns literature describes evaluation and management of burns as being painful and traumatic. ${ }^{12}$

Multiple pediatric institutions have published their experience with management of pediatric SSTIs. These studies have described alternative management for an abscess cavity with the goal of decreasing costs associated with hospital admission for adequate pain control during wound care. Another goal of these studies is to avoid the need for repeated packing of the abscess cavity, for which the burden of dressing care often falls on the family, the pediatrician, or home health care services. ${ }^{9-15}$ These studies are similar in two aspects. First, there is the need for administration of procedural sedation for initial care of an SSTI or traumatic open wound. Second, the setting in which the initial invasive procedure is done to meet the needs for sedation and pain control is the emergency department, intensive care unit, or operating room. Intravenous sedation or general anesthesia is typically given to these patients.

At our institution, we have met the need for both inpatient and outpatient procedural sedation by having a separate team manage complex surgical wounds. We believe this unique model has several advantages for the patient, family, primary care physician, and hospital institution.

\section{Discussion}

The Pediatric Acute Wound Service (PAWS) at St Louis Children's Hospital initially started out as a way to decrease hospitalization of burns patients in an effort to improve resource utilization. ${ }^{16}$ This led to the development of a combined ambulatory burns care service and procedural sedation program. Our successful experience with use of procedural sedation for minor burn debridement was already established and published by Ebach et al during the late 1990s. ${ }^{16}$ By 2001, after demonstrating a significant reduction in length of hospital stay and hospital charges for burns patients, the ambulatory burn care service and procedural sedation program was extended to other pediatric skin and soft tissue conditions needing surgical intervention and/or painful wound care. PAWS began to care for abscesses and other open wounds (pressure ulcers, open surgical incisions, and open traumatic soft tissue wounds). ${ }^{1}$ Our procedural sedation program utilizes pediatric hospitalists instead of pediatric anesthesiologist to administer inhaled or intravenous sedation within our unit. ${ }^{18}$

A pediatric hospitalist is a growing pediatric model that has been defined "as a physician whose primary focus is the general medical care of hospitalized patients". The American Academy of Pediatrics developed guidance for hospitals with regard to having a pediatric hospitalist service. ${ }^{19}$ In 2010 , core competencies were developed and published for this relatively new field. ${ }^{20}$ At our institution, pediatric hospitalists have collaborated with pediatric anesthesiologists to develop a model where specifically trained hospitalists can administer procedural sedation.

PAWS consists of a core group of nurses certified in wound care, a pediatric general surgery nurse practitioner, a pediatric hospitalist trained in procedural sedation, and an available pediatric general surgeon. Due to the increasing number of patients seen by our service on a daily basis, over time we have come to have an assigned child life specialist for our unit and our physical and occupational therapy services provide care within our unit during patient visits. The PAWS environment enables our staff to provide much needed wound care education and teaching for our patients and their families. We are able to provide consistent care for the patient's wound from the beginning to end with each visit. By providing procedural sedation and child life services, the initial SSTI or wound management and following care proceed in a timely manner and with the aim of optimally minimizing anxiety and pain.

The unit is housed within the pediatric hospital and is located on the inpatient surgical floor. Except for patients in the intensive care units (neonatal, pediatric, and cardiac units), the majority of inpatients needing PAWS are transported to the PAWS unit for care alongside outpatients. This allows for inpatients to view their hospital room as a place for recovery, play, and rest. PAWS avoids any delay in wound care and pain management attributed to lack of adequate pain medicine or dressing supplies at the bedside or delay in timely bedside nursing assistance. The PAWS team is maximally efficient in seeing and managing a large volume of patients by remaining in one centralized area instead of traveling throughout the hospital to deliver daily wound care.

Primary care referrals for wounds or SSTIs are seen and cared for in PAWS. Inpatient or outpatient follow-up care continues through PAWS until care is discontinued or transferred 
back to the primary pediatrician. If we anticipate that a patient's wound visit will involve a painful and invasive procedure, patients are evaluated for need for sedation. Our program is limited to sedating patients with an American Society of Anesthesiologists (ASA) physical status category 1 or 2 .

Within our unit, there are rooms equipped with monitors for sedation and dressing supplies, two whirlpools, a waiting area, an intake area, and a workstation area. There are two sedation-capable rooms that act as recovery rooms. There is an additional treatment room for non-sedated patients. Patients are seen 7 days a week, with limited hours on the weekends and holidays. For patients needing wound care in the intensive care units, the PAWS team travels to their bedside.

Often, with complex wounds, multiple providers are involved, such as plastic surgery, infectious diseases, orthopedics, neurosurgery, gastroenterology, the child protection program, and pediatric surgery. Wound care through PAWS is scheduled according to the availability of the patient's primary care team while other consultation services are notified. A sample of the procedures we perform in PAWS and thereby avoid use of the operating room include incision and drainage of SSTIs including complex abscesses, hidradenitis, and pilonidal inflammatory and infectious exacerbations; burn debridement and postoperative graft care; soft tissue foreign body removal; negative pressure wound dressing changes for wounds of all sizes (Figure 1); and open wound dressing changes. We routinely evaluate, diagnose, and manage chronic open wounds for orthopedic and spinal patients with or without instrumentation. Complex ostomies including illfitting gastrostomy appliances in enlarged stomas are treated with careful attention and often require staged wound care to allow the tissues to heal and contract around the gastrostomy button stem. PAWS patients are easily shuttled to and from radiology services, which are utilized routinely for complex

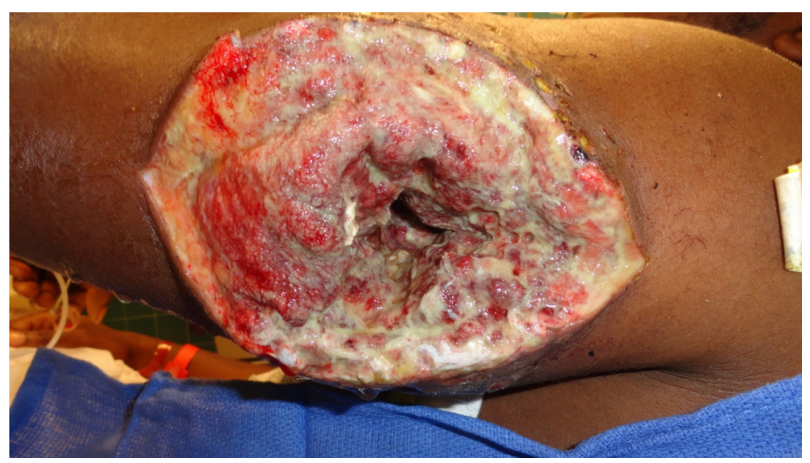

Figure I Large soft tissue defect from a shotgun injury to the left arm that underwent negative pressure wound therapy. wounds with concern for underlying osteomyelitis, retained foreign body, or communication with orthopedic or spine instrumentation. When clinically appropriate, these procedures and diagnostic testing are done on an outpatient basis as long as the patient is medically stable and does not have any other inpatient needs.

Over the past 12 years, patient visits to PAWS have steadily increased. In 2007, 4,757 patient visits were recorded. ${ }^{1}$ Over the past year, we have had 200-400 patient visits per month. Abscesses and burns wounds account for over $50 \%$ of the patient visits (Figure 2). The volume of SSTIs requiring incision and drainage procedures in our emergency department has decreased by $14 \%$ despite the national trend for a significant increase in pediatric SSTI cases. Thus, our PAWS unit seems to be absorbing this dramatic increase in volume while allowing patients to avoid emergency department visits. Pressure ulcers of all stages, orthopedic and spinerelated chronic open wounds, and ostomy care constitute another $25 \%$ of the visits. During the summer months, we see 15-20 patients each week day. During the first 6 years of PAWS, about $50 \%$ of the patient visits involved procedural sedation. Over the following 6 years, we utilized sedation in $40 \%$ of visits. This decrease is likely due to more effective wound care and dressing techniques that involve less pain for the patient. It also coincides with more active involvement of child life services assisting with anxiety management through distraction and education. The percentage of patients needing more than one PAWS visit has remained steady over the past 6 years. About $50 \%$ of our patients needed more than one visit, while $10 \%$ made at least three visits for ongoing wound care.

A majority of our patients are referred for initial SSTI or wound management from their primary care physician or referred for follow-up after initial treatment of their SSTI or wound in the emergency department. Approximately 40\%

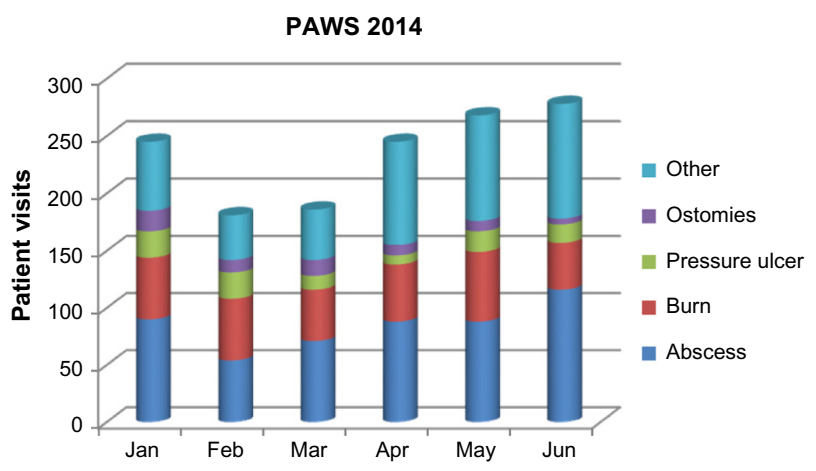

Figure 2 PAWS wound types and visit volume for the first 6 months of 2014 Abbreviation: PAWS, Pediatric Acute Wound Service. 
of our patients are inpatients with a more complex clinical course or wound (unpublished institutional data). Within our institution, hospital costs for labor, equipment, and supplies alone for a 30-minute procedure vary depending on where the procedure occurs, ie, \$150 (PAWS), \$550 (emergency department), and $\$ 943$ (operating room). ${ }^{7}$ These costs do not include provider charges for the proceduralist or sedationist. For PAWS, the surgical providers are most often a nurse practitioner and the sedationist is a pediatrician, while in the emergency department it is a pediatric team. In the operating room, a surgeon and an anesthesiologist deliver the wound care and sedation. Nurse practitioner provider charges are, as expected, decreased in comparison with physician provider charges. In the era of significant health care reform with one of the aims being reduced health care costs, nurse practitioner provided care meets that aim.

We have published on the ability of PAWS to improve cost while not compromising wound care. We have shown a decrease in operating room utilization and a decrease in length of hospital stay from 10.4 days to 5.8 days $(P<0.05)$ in our burns patients treated by PAWS. This resulted in a $45 \%$ reduction in average charges per patient. During this period, wound care was not compromised in that the rates of burns wound infection actually decreased from $5.3 \%$ to $3.0 \%$ with the advent of PAWS. ${ }^{16,17}$

Although the existence of PAWS has decreased inpatient encounters and length of hospital stay, Bucher et al were able to show a $\$ 3.99$ million positive contribution margin by the unit due to its cost-effectiveness. We believe that the advantages of PAWS have resulted in a decreased direct costs associated with wound care while reimbursements remain the same. ${ }^{1}$ These advantages include: avoidance of an initial and/or follow-up emergency department visit; avoidance of an operating room visit when feasible; and avoidance of a prolonged hospital stay for pain management of wounds that require multiple dressing changes and repeated wound care. Additionally, PAWS offers alternative medical providers other than a surgeon and anesthesiologist while still maintaining effective procedural anxiety and pain control through the option of sedation.

Our dedicated daily service unit for pediatric complex wound care is a unique entity that involves a dedicated institution, anesthesiologists, hospital pediatricians, pediatric general surgeons, dedicated wound nurse practitioners, and wound certified nurses.

\section{Conclusion}

Pediatric SSTIs and the need for open wound care are continuing to increase dramatically. The cost associated with these cases are also increasing, and are due to an increased need for surgical intervention and resource utilization in the emergency department, inpatient ward, and operating room. The Pediatric Acute Wound Service at St Louis Children's Hospital is a unique model that meets the increasing demands of pediatric wounds and SSTIs, while not sacrificing patient care on a daily basis. It services both inpatients and outpatients. At the same time, our unit has made a positive contribution margin to the hospital as a result of more costeffective care.

\section{Disclosure}

The author reports no conflicts of interest in this work.

\section{References}

1. Bucher BT, Seigel J, Rosenblum E, et al. A pediatric acute wound service: a novel approach in wound management. J Pediatr Surg. 2010;45(1):167-170.

2. Lopez MA, Cruz AT, Kowalkowski MA, Raphael JL. Trends in resource utilization for hospitalized children with skin and soft tissue infections. Pediatrics. 2013;131(3):e718-e725.

3. Lautz TB, Raval MV, Barsness KA. Increasing national burden of hospitalizations for skin and soft tissue infections in children. J Pediatr Surg. 2011;46(10):1935-1941.

4. National Emergency Department Sample; HCUP Databases. Healthcare Cost and Utilization Project. Rockville, MD, USA: Agency for Healthcare Research and Quality; 2008. Available from: http://www.ahrq.gov/ research/data/hcup/. Accessed May 15, 2015.

5. Guice KS, Cassidy LD, Oldham KT. Traumatic injury and children: a national assessment. J Trauma. 2007;63(6 Suppl):S68-S80.

6. Shields BJ, Comstock RD, Fernandez SA, Xiang H, Smith GA. Healthcare resource utilization and epidemiology of pediatric burnassociated hospitalizations, United States, 2000. J Burn Care Res. 2007; 28(6):811-826.

7. Bernabe KQ, Desmarais TJ, Keller MS. Management of traumatic wounds and a novel approach to delivering wound care in children. Adv Wound Care (New Rochelle). 2014;3(4):335-343.

8. Carey K, Kazis LE, Lee AF, et al; Multi-Center Benchmarking Study Working Group. Measuring the cost of care for children with acute burn injury. J Trauma Acute Care Surg. 2012;73(3 Suppl 2): S229-S233.

9. McNamara WF, Hartin CW Jr, Escobar MA, Yamout SZ, Lau ST, Lee YH. An alternative to open incision and drainage for community-acquired soft tissue abscesses in children. J Pediatr Surg. 2011;46(3):502-506.

10. Leinwand M, Downing M, Slater D, Beck M, Burton, K, Moyer D. Incision and drainage of subcutaneous abscesses without the use of packing. J Pediatr Surg. 2013;48(9):1962-1965.

11. Alder AC, Thornton J, McHard K, Buckins L, Barber R, Skinner MA. A comparison of traditional incision and drainage versus catheter drainage of soft tissue abscesses in children. J Pediatr Surg. 2011;46(10):1942-1947.

12. Stoddard FJ Jr, White GW, Kazis LE, et al. Patterns of medication administration from 2001 to 2009 in the treatment of children with acute burn injuries: a multicenter study. J Burn Care Res. 2011;32(5): 519-528.

13. Tsoraides SS, Peral RH, Stanfill AB, Wallace LJ, Venguta RK. Incision and loop drainage: a minimally invasive technique for subcutaneous abscess management in children. J Pediatr Surg. 2010;45(3): 606-609.

14. Ladd AP, Levy MS, Quilty J. Minimally invasive technique in treatment of complex, subcutaneous abscesses in children. J Pediatr Surg. 2010;45(7):1562-1566. 
15. Wright TN, Gilligan L, Zhurbich O, Davenport DL, Draus JR Jr. Minimally invasive drainage of subcutaneous abscesses reduces hospital cost and length of stay. South Med J. 2013;106(12):689-692.

16. Foglia RP, Moushey R, Meadows L, Seigel J, Smith M. Evolving treatment in a decade of pediatric burn care. J Pediatr Surg. 2004;39(6): 957-960.

17. Ebach DR, Foglia RP, Jones MB, et al. Experience with procedural sedation in a pediatric burn center. J Pediatr Surg. 1999;34(6):955-958.

18. Turmelle M, Moscoso LM, Hamlin KP, Daud YN, Carlson DW. Development of a pediatric hospitalist sedation service: training and implementation. J Hosp Med. 2012;7(4):335-339.
19. Friedman J. The hospitalist movement in general pediatrics. Curr Opin Pediatr. 2010;22(6):785-790.

20. Stucky ER, Maniscalco J, Ottolini MC, et al. The pediatric hospital medicine core competencies supplement: a framework for curriculum development by the society of hospital medicine with acknowledgement to pediatric hospitalists from the American Academy of Pediatrics and the Academic Pediatric Association. J Hosp Med. 2010;5 Suppl 2:i-xv, $1-114$.

\section{Publish your work in this journal}

Chronic Wound Care Management and Research is an international, peer reviewed, open access, online journal publishing original research, reviews, editorials, and commentaries on the causes and management of chronic wounds and the major issues related to chronic wound management. Topics also include chronic wounds as comorbidities to other conditions, patient adherence to therapy, and the economic burden of chronic wounds. The manuscript management system is completely online and includes a very quick and fair peer review system, which is all easy to use. Visit http://www.dovepress.com/testimonials.php to read real quotes from published authors.

Submit your manuscript here: http://www.dovepress.com/chronic-wound-care-management-and-research-journal 